5. Торбоков, А. Алтай шатра. Правила и комбинации в шатре. - Горно-Алтайск : The first step, 2013. - $34 \mathrm{c}$.

6. Теория и история игры / [редкол. : В. М. Григорьев, С. В. Григорьев (отв. ред.) и др.]. - Вып. 1 : Памяти Е. А. Покровского. - Москва : ODU-International, 1995. - 108 с.

7. Сатлаев, Ф. А. Кумандинцы (историко-этнографический очерк XIX - первой четверти XX в.). - Горно-Алтайск : [Алт. кн. изд-во], 1974. - 200 с.

8. Краткий словарь этнографических и фольклорных понятий и терминов / сост. : В. П. Ойношев. - Горно-Алтайск : [...], 2011. - 90 с.

Igor L. Musukhranov

Altai State Institute of Culture (Barnaul, Russia) eni4ka@mail.ru

\title{
RELATION BETWEEN ALTAIANS' PEOPLE'S GAME AND ALTAIAN TRADITIONAL CHOREOGRAPHY: PROBLEM STATEMENT
}

\begin{abstract}
The paper considers a relation between dance and plastic culture of Altaians and some symbolic and artistic images, plot devices of feast and ritual complex and ritual people's games of the indigenous Turkic people of Altai. On the author's opinion, choreographic thinking of Altaians (in dramaturgy, imagery, rhythm, structure of dance) developed under the influence of people's culture, traditional cults. A need of further scientific examination of historical and ethnographic materials reveal traditional culture of Altaians in the context of approximation of today's version of folk stage dance to original examples of Altaian ethnos' choreographic art is stressed out.

Keywords: Altaians, Altaians' mythology, Altaian people's dance, traditional choreography of peoples of Altai, people's games, outdoor physical games, mythic images, a game, competitive games.
\end{abstract}

УДК 338.482.224:910.4-51(570.150+570.151)

DOI: 10.32340/2414-9101-2021-1-27-34

М. В. Рыгалова, кандидат исторических наук Алтайский государственный университет (Барнаул, Россия) mariya_rygalova@mail.ru

\section{ВКЛАД ИССЛЕДОВАТЕЛЕЙ В ИЗУЧЕНИЕ АЛТАЯ: К ВОПРОСУ ОБ АКТУАЛИЗАЦИИ НАСЛЕДИЯ}

\begin{abstract}
Исследование выполнено при финансовой поддержке Совета по грантам Президента Российской Федераџии, проект № МК-4173.2021.2 «По маршрутам исследователей и путешественников Алтая: актуализащия наследия средствами ГИС-технологий»
\end{abstract}

Аннотация. Рассмотрены общие вопросы интеграции краеведческого историкокультурного наследия в сферы внутреннего экскурсионно-познавательного, рекреационного туризма на Алтае. Охарактеризован образовательно-просветительный потенциал научной реконструкции и популяризации в среде потребителей туристических услуг крупных маршрутов отечественных и иностранных исследователей Алтая, путеше- 
ственников XVIII-XIX вв., чьи имена связаны с крупными открытиями в области региональной этнографии, геологии, ботаники и др.

Ключевые слова: историко-культурное наследие, научное краеведческое знание, региональный познавательный туризм, актуализаџия историко-культурного наследия, Алтайский край, Республика Алтай, исследователи Алтая, путешественники.

Историко-культурное наследие неизменно является ценным ресурсом в развитии культурной и социальной составляющей общества. Все больший интерес сегодня вызывает возможность актуализации исторического наследия и возможности его адаптации к меняющимся тенденциям. Это связано, в том числе, с изменениями, происходящими в духовной сфере. Изучение и популяризация наследия позволяют народу поддерживать и сохранять свою самобытность, духовность. Несмотря на тенденции к глобализации, к вопросам историко-культурного наследия следует подходить с учетом региональной специфики, учитывая уникальное историческое богатство территории.

Актуализация наследия - деятельность, направленная на сохранение и включение культурного и природного наследия в современную культуру путем активизации социокультурной роли его объектов и их интерпретации [1, с. 39]. Историко-культурное наследие обладает богатым образовательным потенциалом, способствует воспитанию патриотических чувств, развитию интереса к истории. Приобщение к историкокультурным ценностям во многом связано с познанием региональной истории. Использование образовательного потенциала культурного наследия и предполагает его актуализацию [2].

Обращение к историко-культурному наследию способствует изучению уникальных особенностей страны, региона, позволяет оценить их ресурсный потенциал. Историкокультурное наследие следует рассматривать не просто как то, что нужно сохранить, но с точки зрения общественных ценностей, которые формируют национальную идентичность, подчеркивают особенности страны, отдельной территории. Включение ресурсов наследия в туристическую отрасль позволяет говорить о его экономической составляющей [3].

Краеведческие знания становятся все более востребованными. В этой связи видится перспективность изучения направления, которое связано с актуализацией наследия отечественных и зарубежных исследователей как для историков, краеведов, представителей других научных направлений (географов, биологов и проч.), а также для туристов, которые все чаще выбирают Алтай в качестве места отдыха.

С точки зрения истории конкретной территории большой интерес вызывает вклад выдающихся личностей в развитие региона, а также отслеживание процесса сохранения наследия, которое они оставили или создали, будучи на территории. Если в начале XVIII в. об Алтае было известно немного, то сегодня эта территория является одной из наиболее востребованных у туристов. Однако многие, находясь в регионе, не используют весь его потенциал. С этой целью нужна актуализация и популяризация наследия. Интерес к маршрутам исследователей Алтая может быть также со стороны самих жителей региона.

Актуализация наследия исследователей Алтая позволит собрать в едином комплексе информацию о маршрутах, с их описанием, реконструировать их и отразить в совре- 
менном пространстве с перспективой повторения, а также разрабатывать туристические направления по историческим местам и углублять краеведческие знания. Кроме того, анализ информации об исследованиях Алтая позволит выявить их особенности и тематику в конкретные периоды, обратить внимание на интересы исследователей и процессы развития и накопления историко-краеведческих, естественнонаучных знаний о регионе.

В качестве территориальных рамок исследования выбраны Алтайского край и Республика Алтай, поскольку большинство исследователей через современную территорию края направлялись для изучения горной части региона. Это связано и с тем, что в историческом контексте территории Алтайского края и Республики Алтай входили в состав Колывано-Воскресенского (Алтайского (горного) округа).

Хронология изучения охватывает XVIII-XIX вв., как период наиболее активного изучения территории исследователями.

Привлекательность территории Алтайского края для туристов во многом связана, в числе прочего, с известными именами, на которые богат регион. Это, прежде всего, знаменитые актеры, писатели (В. М. Шукшин, Р. И. Рождественский, В. С. Золотухин и проч.) Республика Алтай интересует туристов, прежде, всего, с рекреационной точки зрения. Однако привлекательность территории можно увеличить, популяризируя историко-культурные сведения о регионах. Поскольку многие исследователи являлись иностранными, изучение их вклада в исследование Алтая будет способствовать дополнительному интересу именно со стороны зарубежных туристов.

$\mathrm{C}$ научно-исследовательской точки зрения, изучение наследия, а также восстановление маршрутов, позволит упорядочить данные по исследованию территории Алтая (хронологию, направления, тематику), собрать воедино персональное наследие ученых, побывавших на Алтае и внесших свой вклад в его развитие, актуализировать и популяризировать данные как о самих исследователях-путешественниках, так и о том наследии, которое они оставили в результате посещения Алтая, собрать информацию и составить библиографию научных трудов об Алтае, которые были опубликованы в ведущих российских издательствах.

Тема популяризации историко-культурного наследия в контексте развития внутреннего познавательного туризма становится всё более актуальной. Это связано со стремлением каждого региона сохранить и представить свои культурно-исторические особенности, связи с выдающимися личностями, исследователями, оценкой их вклада в развитие региона, направлений его развития.

Сегодня спросом среди туристов пользуются исторические, военно-исторические, культурно-исторические маршруты. Так, в 2014 г. Федеральное агентство по туризму и Российское военно-историческое общество заключили соглашение о сотрудничестве в сфере военно-исторического туризма. В этом направлении власть и исследователи видят перспективы привлечения туристов, поскольку тема является актуальной для разновозрастной аудитории, а также важной с точки зрения развития патриотизма. Военно-исторические маршруты являются одними из востребованных в рамках познавательного туризма [4, с. 64-65].

Со стороны туристов вызывают интерес и более масштабные проекты. Так, например, имеется прецедент повторения маршрута Н. Н. Миклухо-Маклая на Новую Гвинею. Организатором являлся фонд этнокультурного наследия Н. Н. Миклухо-Маклая, а одним из участников и инициаторов явился потомок исследователя и его полный тезка 
[5]. Регионы активно исследуют потребности иностранных туристов с целью разработки оптимальных маршрутов [6, с. 91-93].

Однако не только туристические цели преследуются при организации экспедиций по маршрутам ученых-путешественников. Очень часто они неразделимы с научными целями и, конечно, всегда направлены на актуализацию и популяризацию научного и историко-культурного наследия. Примерами этому являются организованные Русским географическим обществом и его региональными филиалами ряд крупных экспедиций, экспедиции ученых крупных европейских и российских высших учебных заведений. Так, целая череда экспедиционных мероприятий с научными и популяризационными целями была проведена в 2019 г. в связи с 250-летием со дня рождения немецкого ученого В. Гумбольдта. Совместный проект немецких и российских географов предусматривал повторение маршрута ученого от Берлина до Сибири, с целью укрепления сотрудничества в области геологических находок и исследований, а также популяризации наследия В. Гумбольдта [7]. К этому же событию был приурочен трехдневный велопробег, организованный туристической компанией «Русский Алтай» по территории Алтайского края, где пролегал маршрут В. Гумбольдта (г. Барнаул - оз. Колыванское с. Каменка - п. Колывань - п. Черепановск - г. Змеиногорск - г. Барнаул) [8].

В 2012 г. отделение русского географического общества Кургана организовало реконструкцию путешествия П.С. Палласа от границы Челябинской и Курганской областей до Кургана В 2014 г. биологи Тюменского государственного университета подхватили эту идею, восстановили и прошли экспедиционный маршрут академика П. С. Палласа по Курганской и Тюменской областям. В этих экспедициях исследователи, также, как и Паллас, обращали внимание на фауну. При чем, исследователи отмечают не только научный интерес к повторению маршрута, но и возможность популяризации наследия немецкого ученого [9]. В Республике Башкортостан туристической компанией организован маршрут «По следам Петра Симона Палласа», побывавшего на этой территории в 1777 г. с научными целями [10]. В 2018 г. члены Русского географического общества организовали экспедицию «По следам Палласа», проехав на снегоходах более 150 км. По территории Башкортостана Русское географическое общество. Отделение в Республике Башкортостан [11].

Таким образом, тема актуализации наследия исследователей-путешественников и популяризации их деятельности является востребованной как в научных, так и широких кругах. Однако в Алтайском крае и Республики Алтай, несмотря на то, что эти территории были очень посещаемы, случаи обращения к персональному наследию на уровне практической реконструкции маршрутов единичны.

Начало научному изучению Сибири положил Петр I в первой половине XVIII в., когда были организованы экспедиции для изучения истории, географии, быта населения [12, с. 39]. Позже к этим направлениям добавляются изучение флоры и фауны.

Территория Алтайского края вошла в состав России в XVIII в. С этого времени начинается богатая история региона, который становится центром горной промышленности. Алтай привлекал исследователей и путешественников, которые изучали его промышленность, природные богатства, историю, этнографию. Некоторые фамилии часто звучат сегодня, другие имена забыты и мало востребованы в исторической науке, в том числе истории Сибири и Алтая, но их вклад в историко-культурное и научное развитие региона не менее значим. 
Территории современных Алтайского края и Республики Алтай посещали многие исследователи и путешественники, оставившие существенное наследие и внесшие значимый вклад в развитие региона, среди них С. У. Ремезов, И. Г. Гмелин, Г. Ф. Миллер, Ф. В. Геблер, В. В. Радлов, С. И. Гуляев, А. Гумбольдт В. И. Верещагин, Г. Н. Потанин, Н. М. Ядринцев, В. В. Сапожников и др. Результатами их исследований и путешествий явились карты, научные труды, описания местности. Кроме того, ценность представляют для краеведения и туризма сами маршруты, которые были проложены учеными.

Историко-культурное наследие сегодня в мире рассматривается в качестве мощного ресурса развития региона [13, с. 140-141]. Каждая территория по-своему уникальна вне исторического контекста, однако он придает еще большую ценность.

Роль и значение сохранения и развития краеведческих знаний трудно переоценить. Краеведение способствует накоплению исторических знаний, развитию патриотического воспитания, любви к малой родине. Историческое краеведение тесно связано с широким комплексным изучением конкретной территории, что является важным в глубоком познании прошлого и настоящего, осознании перспектив в развитии культуры общества в целом [14].

С учетом ориентации в региональном развитии на туристический потенциал, возникает необходимость развития тех сфер, которые позволят привлечь туристов, в том числе для посещений в познавательных целях. Для этого необходима мобилизация культурных центров и научного сообщества.

Разработка экскурсионных программ и материалов, направленных на актуализацию местного исторического и культурного наследия, способствующая сохранению коллективной памяти и привлечению новых аудиторий.

Изучению вклада исследователей и путешественников двух Алтаев посвящены обобщающие работы, одной из которых является Библиографический словарь «Исследователи Алтайского края XVIII - начала XX в.», который включает в себя более 400 фамилий ученых в области истории, географии, биологии, геологии и других областях знания. В нем содержится краткая биографическая справка, сведения о маршрутах, а также литературу и ссылки на архивные фонды Государственного архива Алтайского края, в которых можно уточнить и расширить данные по конкретной личности ученого [15]. Работа Н. Камбалова «Исследователи Алтая» посвящена описанию путешествий П. Шелегина, П. Попова, Э. Лаксмана, П. Палласа, К. Ледебура, Ф. В. Геблера [16]. Огромную работу по изучению наследия исследователей Алтая, упорядочению данных проделал А. Д. Сергеев [17]. Все эти работы объединяет биографический принцип изложения материала, краткая справка о местах путешествия. Чаще всего исследователи, ученые прибывали на территорию региона с целью изучения горного производства, а также предгорной и горной территории, большая часть которой по современному административно-территориальному делению относится к Республике Алтай.

В рамках нашего исследования важной задачей видится расширение сведений о маршрутах, которые часто в указанных выше и других работах представлены обобщенно (справочно), а также разделение информации о маршрутах по Алтайскому краю и Республике Алтай. Несомненно, для исследователей-путешественников XVIII-XIX вв. стояла задача осуществления единого маршрута на территории КолываноВоскресенского (Алтайского (горного) округа), и часто целями изучения были территории, сегодня относящиеся к Республике Алтай, поэтому эту часть маршрута мы 
не можем упустить из обозрения, однако, в большей степени наш интерес сводится к изучению именно территории Алтайского края в его современных границах.

Исследование предполагается выстроить по персоналиям и направлениям изучения (история, биология, этнография и проч.), а также обобщить данные по тематикохронологическому принципу (интерес к отдельным темам в конкретных хронологических границах, например, изучение горного производства на Колывано-Воскресенских заводах и проч.)

Источниковой базой исследования являются обобщающие работы в области исследований Алтая, опубликованные труды ученых-путешественников, находящиеся в фондах Алтайской краевой универсальной научной библиотеки им. В. Я. Шишкова, Президентской библиотеки им. Б. Н. Ельцина, а также неопубликованные данные из фондов Государственного архива Алтайского края, в которых представлены сведения о деятельности на территории Алтая исследователей.

Актуализация наследия сегодня очевидна. От знания и понимания своей истории, культуры зависит уровень развития общества, а значит, государства в целом. Исследователи Алтая внесли огромный вклад в освоение территории. Именно в XVIII-XIX вв. закладывались научные, историко-культурные основы развития территории, во многом именно благодаря исследователям, современные территории Алтайского края и Республики Алтай были изучены и описаны учеными различных областей, стали широко известными в масштабах Российской империи.

\section{Список литературы}

1. Словарь актуальных музейных терминов // Музей. - 2009. - № 5. - С. 47-68.

2. Дёмина, С. А. Актуализация образовательного потенциала культурного наследия в современном культурно-образовательном пространстве // Современная педагогика. 2014. - № 3. - URL: http://pedagogika.snauka.ru/2014/03/2149 (дата обращения: 11.09.2020).

3. Румянцев, М. В. Актуализация историко-культурного наследия / М. В. Румянцев, А. П., Свитин В. С. Ефимов, А. В. Лаптева // Информационный бюллетень Ассоциации «История и компьютер». - 2010. - № 36. - С. 23-25.

4. Минаев, В. А. Маршруты в героическое прошлое // Высшее образование сегодня. - 2014. - № 10. - С. 64-72.

5. Экспедиция «Миклухо-Маклай XXI век. Берег Маклая». Путешествие в потерянный рай // Фонд сохранения этнокультурного наследия им. Миклухо Маклая : [сайт]. - Санкт-Петербург, 2016-2021. - URL: https://mikluho-maclay.ru/puteshestvie-vpoteryannyj-raj/ (12.01.2021).

6. Фирсова, А. В. Образовательный туризм в Пермском крае / А. В. Фирсова, С. Э. Мышлявцева. - Пермь : Перм. гос. нац. ун-т, 2014. - 149 с.

7. По следам Гумбольдта: экспедицию немецкого географа в России повторят спустя 190 лет // «Форпост Северо-Запад» : интернет-издание : [сайт]. - Санкт-Петербург, 2017-2021. - URL: https:/forpost-sz.ru/a/2019-04-22/po-sledam-gumboldta-ehkspediciyunemeckogo-geografa-v-rossii-povtoryat-spustya-190-let (дата обращения 12.03.2021).

8. По следам Гумбольдта на Алтае // Всемирная энциклопедия путешествий : [сайт]. - Москва, 2013-2021. - URL: https://planetguide.ru/krugosvetka/exp/po_sledam_ gumboldta_na_altae/po_sledam_gumboldta_na_altae/ (дата обращения 12.03.2021). 
9. Гашев, С. Н. П оследам экспедиции П. С. Палласа в Южном Зауралье // Aus Sibirien - 2015 : науч.-инф. сб. - Тюмень : ТюмГУ, 2015. - С. 44-47.

10. По следам Петра Симона Палласа // Юрюзань-Тур : [сайт]. - URL: https://yutour.ru/tour/po-sledam-petra-simona-pallasa (дата обращения 12.03.2021).

11. Снегоходная экспедиция «По следам Палласа» // «Русское географическое общество», Всерос. общ. орг-ция. - Москва, 2013-2021. - URL: https://www.rgo.ru/ru/article/snegohodnaya-ekspediciya-po-sledam-pallasa (дата обращения 12.03.2021).

12. Андреев, А. И. Очерки по источниковедению Сибири. - 2-е изд., испр. и доп. Москва ; Ленинград : Изд-во Акад. наук СССР. [Ленингр. отд-ние], 1960-1965. - 2 т. Вып. 2: XVIII век. (Первая половина). - 1965. - 364 с.

13. Антропов, А. Е. Актуализация и визуализация историко-культурного наследия как форма самопрезентации городского сообщества (на примере общественных практик Новосибирска) // Вестник Новосибирского государственного университета. - 2013. -Т. 13, № 3. - С. 140-148.

14. Путрик, Ю. С. Культурное и природное наследие как важный фактор патриотического воспитания молодёжи в Российской Федерации / Ю. С. Путрик, А. П. Соловьёв, П. Е. Царьков // Журнал Института наследия. - 2015. - № 2. - URL: http://naslediejournal.ru/ru/journals/21.html (дата обращения: 12.01.2021).

15. Исследователи Алтайского края. XVIII - начало XX в. : биобиблиогр. словарь. - Барнаул : Алт. полигр. комбинат, 2000. - 280 с.

16. Камбалов, Н. Исследователи Алтая (XVIII и первая половина XIX века). Барнаул : Алт. кн. Изд-во, 1956. - 58 с.

17. Сергеев, А. Д. История Алтайского края в трудах исследователей и путешественников (конец XVIII - первая половина XIX вв.) : автореф. дис. ... канд. ист. наук: 07.00.09. - Томск, 1973. - 24 с.

Mariia $\boldsymbol{V}$. Rygalova, Ph. D. in History Altay State University (Barnaul, Russia) mariya_rygalova@mail.ru

\title{
CONTRIBUTION OF RESEARCHERS TO THE STUDY OF ALTAY: TO THE ACTUALIZATION OF THE HERITAGE
}

The reported study was founded by Grant Council of the President of the Russian Federation according to research project no. 4173.2021.2 "In the Footsteps of Explorers and Travelers of Altai:

popularization of heritage by means of GIS-technologies",

\begin{abstract}
The paper is dedicated to general issues of integration of historical and cultural heritage into spheres of domestic educational and recreational tourism in Altai region, outlines educative potential of scientific reconstruction and popularization of big routes of Russian and foreign Altai (Russia) explorers and travelers of the $18^{\text {th }}-19^{\text {th }}$ centuries whose names are related with breakthroughs in regional ethnography, geology, botany, etc. among touristic service consumers.
\end{abstract}


Keywords: historical and cultural heritage, scientific local lore, regional educational tourism, popularization of historical and cultural heritage, Altai Krai, Altai Republic, explorers of Altai, travelers.

УДК 379.8.000.93

DOI: $10.32340 / 2414-9101-2021-1-34-41$

Т. Т. Фисюк, кандидат педагогических наук, доцент Алтайский государственный институт культуры (Барнаул, Россия) tatfis@inbox.ru

\section{КЛУБНЫЙ ВЕЧЕР \\ КАК СОВРЕМЕННАЯ КУЛЬТУРНО-ДОСУГОВАЯ ПРОГРАММА: ИСТОРИКО-ТЕХНОЛОГИЧЕСКИЙ АСПЕКТ}

Аннотация. Исторические предпосылки возникновения первых тематических клубных вечеров как формы коллективного организованного досуга сложились ещё в Древнем мире. К концу XVIII в. в России клубные вечера становятся распространённым в дворянской среде гостевым видом общения. События революционного октября 1917 г. повлекли за собой коренные политико-экономические, идеологические и культурные перемены, отразившиеся в т. ч. на подходах к организации массовых и групповых досуговых практик граждан нового советского государства. Аргументирована авторская точка зрения, согласно которой тематический вечер вплоть до 1980-х гг. становится одной из самых востребованных населением массовых форм художественной пропаганды. Изложено авторское определение понятия «тематический вечер», представлено описание типовой композиционной структуры тематического вечера. Охарактеризован ряд современных тенденций в области организации досуговых практик населения, которые режиссёру-постановщику культурно-досуговых программ необходимо учитывать в контексте реализации технологии подготовки современных тематических клубных вечеров.

Ключевые слова: клуб, клубный вечер, гостевая форма общения, клубные вечеринки, виды тематических клубных вечеров, структура театрализованного тематического вечера, тематический вечер как культурный продукт, клубный сегмент индустрии досуга.

Предпосылки клубных вечеров как формы организованного досуга возникли в глубокой древности. Для полноценного отдыха и восстановления жизненных сил человеку всегда было свойственно стремление сменить обстановку, окружение и сферу собственных действий. Вечер - это условно временное понятие, которое предполагает наличие свободного времени у человека после завершения своей общественной, трудовой, производственной и пр. деятельности. Как правило, оно появлялось в конце трудового дня и приходилось на вечер как времени суток. Для вечернего совместного провождения времени выбирался определенный социальный круг себе подобных. 